\title{
Emotional exhaustion is associated with work related stressors: a cross-sectional multicenter study in Malaysian public hospitals
}

\author{
Erwin J. Khoo, M.D. ${ }^{a}$, Sami Aldubai, M.D., Mg. ${ }^{b}$, Kurubaran Ganasegeran, M.D. ${ }^{c}$, \\ Bernice X. E. Lee, student ${ }^{d}$, Nurul A. Zakaria, student ${ }^{d}$ and Kah K. Tan, M.D. ${ }^{e}$
}

\begin{abstract}
Introduction. Emotional exhaustion is an important component of burnout. Burnout is common among doctors. It affects the physical and mental health of doctors, their performance and the quality of care they provide. This study aimed to investigate the level and factors associated with emotional exhaustion among doctors in pediatric practice in Malaysia.

Population and methods. A self-administered questionnaire was used in this multicenter cross-sectional study. It included questions on the socio-demographics, work characteristics, Emotional Exhaustion, Perceived Stress Scale and sources of job stress. Descriptive, univariate and multivariate analysis were conducted using the SPSS software.

Results. A total of 197 doctors working in the Pediatric department in eight hospitals returned complete questionnaire. High and moderate emotional exhaustion was reported by $25.4 \%$ and $24.4 \%$ doctors, respectively. In bivariate analysis, 29 out of the 38 items of sources of stress showed significant association with emotional exhaustion $(p<0.05)$.The significant predictors of emotional exhaustion in the multivariate analysis were: scoring higher on the Perceived Stress Score, dealing with patient's psychosocial problems, disrespectful interactions with colleagues/ subordinates, lack of appreciation from supervisors, lack of incentives and promotions, time pressures and deadlines to meet, and setting unrealistic goals of having them imposed on oneself $(p<0.05)$. The most common source of stress was dealing with difficult parents $(80.2 \%)$. Conclusions. Emotional exhaustion is associated with sources of stress in the workplace but not with socio-demographic factors.
\end{abstract}

Key words: burnout, professional; pediatrics; stress; workplace.

http: / / dx.doi.org/10.5546/ aap.2017.eng.212

This study and its cash incentives for subjects as token of appreciation was funded from the International Medical University Research Grant(CSc/ Sem6(36)2014).

Conflict of interest: At the time of submission, Tan Kah Kee was Head of Pediatric Department at the Tuanku Ja'afar Seremban Hospital.

Received: 6-13-2016 Accepted: 10-24-2016

\section{INTRODUCTION}

Burnout, a condition of emotional exhaustion affecting professionals in contact with people, ${ }^{1}$ is an important occupational hazard in clinical services in hospital.
To cite: Khoo EJ, Aldubai S, Ganasegeran K, et al. Emotional exhaustion is associated with work related Malaysian public hospitals. Arch Argent Pediatr 2017;115(3):212-219.
It is known that burnout is a major problem in Pediatric departments. ${ }^{2-6}$ There are many putative factors such as the stress of intensive neonatal care, ${ }^{7}$ the challenging adolescent, child custody issues, child abuse ${ }^{8}$ as well as the frequent need for interaction and careful communication with patients and their worried families. Pediatric subspecialists also have level of stress that raises significant concerns. ${ }^{9-11}$ Although many published studies have described the prevalence of burnout in pediatric settings, to our knowledge the factors that contribute to burnout have not been documented.

This type of moral distress can lead to impaired quality of professional care, poor doctor-patient relationship, decreased empathy, ${ }^{12}$ increased medical errors, ${ }^{13}$ low job satisfaction, attrition from the profession, conflict among colleagues ${ }^{14}$ substance abuse ${ }^{15}$ and even suicide (attempted or accomplished) $)^{16,17}$ These factors can compromise the efficacy of the healthcare system and expose doctors to litigation.

As children remains one of the most vulnerable patient group in the hospital ${ }^{18}$ measures to improve optimal delivery of pediatric care are imperative to ensure that these healthcare providers are in a functional capacity to deliver their best in providing for children.

The purpose of this multicentre study was to determine the prevalence of emotional exhaustion in pediatric doctors (from house officers to specialist pediatricians) and to seek associated factors. We hypothesised that emotional exhaustion is linked to workplace factors. Avoidance or mitigation of these factors could lead to improvement in the provision of 
child healthcare and also overcome some of the negative perceptions of Pediatrics as a career.

\section{POPULATION AND METHODS Study Setting and Population}

Pediatric Healthcare in Malaysia is mainly the responsibility of the Ministry of Health. It implements a universal healthcare system, which co-exists with the private healthcare system used mainly for elective pediatric procedures.The population of Malaysia in 2014 was estimated at 29.9 million, with $25 \%$ aged less than 14 years old $^{19}$ and a total of 748 registered pediatricians in the country since year 2001 -one per 10,000 children-. ${ }^{20}$

A total of 53 public hospitals with pediatrician(s) mainly manage the bulk of secondary acute child healthcare in the country. These hospitals accept admission of children less than 12 year-old, with some chronic childhood illnesses managed until the age of 18 . The infant mortality rate is $6 / 1000$ live births comparable to European countries. ${ }^{19}$

This cross-sectional study multicenter was conducted in eight public hospitals in Malaysia. A purposive typical case and maximum variation sampling strategy was used to ensure the selection of nationally representative sample of Pediatrics departments in public hospital. This type of sampling strategy was centered on: (1) geographical distribution and population density of the country (one hospital from Northern Region of West Malaysia; one hospital from East Malaysia; two hospitals from Southern Region of West Malaysia; and four hospitals from Central Region of West Malaysia where population are most dense in the country), (2) its designated tertiary referral state hospitals, (3) number of hospital beds; and (4) hospital with graduate housemanship training. We included all Ministry of Health doctors in those Pediatrics departments i.e. all house officers, medical officers, and specialist pediatricians in the crosssectional multicenter study. Subjects with less than two months of active clinical pediatric experience and those who have no contact with pediatric patients were excluded. Doctors that are attached to the hospital who were employed by a university or an academic center (not from the Ministry of Health) were also excluded in the study.

\section{Survey administration}

Heads of Departments in the eight sampled hospitals were invited to participate by official letters. Endorsements were obtained from national specialty organizations, and cover letters were included in specified mailings. A pediatrician from each hospital were identified and explained of the purpose and procedure of the study through a telephone conversation. The questionnaires with consent, simple instructions and information sheet were couriered with a reply envelope and paid postage to the identified pediatrician, except for the four hospitals in the Central Region of West Malaysia. Then, the consent form and questionnaires were distributed to all doctors within the department by the identified pediatrician during the following sessions where all doctors meet: Grand Ward Round sessions, Morning Hand-over sessions, and during Departmental Meetings. All participants were provided with standardized written and verbal instructions regarding survey completion and the anonymous collection of the data. All participants signed a consent form at the time of questionnaire distribution. Participants were requested to enter their Malaysian Medical Council Registration Number. This number was entered into the registration database to ensure respondents validity. The completed surveys were collected immediately at the end of the sessions, and by four weeks, all responses were couriered back to the authors. A direct approach was used for the Pediatric departments in the Central Region of West Malaysia, where surveys were distributed and collected by two co-authors personally. Completion of the surveys was optional; however, to encourage participation, doctors were given cash incentives of MYR 5 (USD 1.20) upon survey completion as token of appreciation.

\section{Instruments}

A self-administered questionnaire consisting of four parts was applied. The first part included questions on socio-demographics and work characteristics (gender, age, ethnicity, marital status, position, university graduated, number of average calls per month, and duration of working experience). The remaining parts included the Emotional Exhaustion (EE) subscale, the Perceived Sources of Job Stress, and the Perceived Stress Scale-10 (PSS-10) which were previously validated in a local setting. ${ }^{21-24}$

We measure emotional exhaustion using the EE subscale of the validated Maslach Burnout Inventory Human Service Survey (MBI-HSS). 
The EE subscale consists of 9 items which were answered by the respondents in terms of the frequency they experienced these feelings, on a 7-point Likert scale ranging from 0 (never) to 6 (everyday). A higher score indicated greater EE and accordingly, a higher emotional burnout. ${ }^{21}$ This instrument was validated in many previous studies. The Cronbach's alpha coefficient of the EE subscale reported here was 0.93 . The factorial structure in the literature yielded one factor for the nine items of EE subscale. In this study the exploratory factor analyses of EE yielded one factor with given value greater than 1 (6.3). The one-factor solution accounted for $69.692 \%$ of the variance.

The Perceived Sources of Job Stress were assessed by using 38 items gathered by literature review. Respondents were asked "Do you think the following aspect is a source of stress to you?" The response for each item was optioned "Yes" or "No". Examples of sources of stress in this study included "fear of medical errors", "work overload on calls an long working hours", "family commitments and obligations" and "hostile workplace environment". These questions were analysed individually, and not in a collective manner. The corresponding Cronbach's alpha coefficient was 0.874 .

Perceived stress was measured by using the PSS-10 which allows assessing the degree of stressfulness perceived by each person. ${ }^{22}$ The participants were asked to respond to each question on a 5-point Likert scale ranging from 0 (never) to 4 (very often), indicating how often they had felt stressed within the past month. The scores ranged from 0 to 40 , where higher scores indicated greater perceived stress. ${ }^{23}$ The Malay version of PSS-10 was a validated measure of stress in the Malaysian population with satisfying psychometric properties and with a Cronbach's alpha coefficient of $0.71 .^{22,23}$ The Cronbach's alpha coefficient of the perceived stress scale used in this study was 0.843 .

\section{Ethical considerations}

This research protocol and its funding was registered and approved by the Joint Committee on Research \& Ethics, International Medical

TABLE 1: Socio-demographics of respondents and its association with emotional exhaustion $(n=197)$

\begin{tabular}{|c|c|c|c|}
\hline Characteristics & $\mathbf{N}(\%)$ & Mean (SD) & $p$ value \\
\hline \multicolumn{4}{|l|}{ Gender } \\
\hline Male & $54(27.4)$ & $19.9(12.2)$ & \multirow[t]{2}{*}{0.328} \\
\hline Female & $143(72.6)$ & $18.0(11.4)$ & \\
\hline \multicolumn{4}{|l|}{ Age } \\
\hline Less than 30 years old & $121(61.4)$ & $17.7(11.1)$ & \multirow{2}{*}{0.210} \\
\hline 30 years old and above & $76(38.6)$ & $19.9(12.4)$ & \\
\hline \multicolumn{4}{|l|}{ Ethnicity } \\
\hline Malay & $93(47.2)$ & $19.4(11.3)$ & \multirow[t]{3}{*}{0.126} \\
\hline Chinese & $76(38.6)$ & $19.0(11.0)$ & \\
\hline Indian & $28(14.2)$ & $14.4(13.7)$ & \\
\hline \multicolumn{4}{|l|}{ Marital status } \\
\hline Single & $94(47.7)$ & $18.0(10.8)$ & \multirow{2}{*}{0.570} \\
\hline Married/Cohabiting & $103(52.3)$ & $19.0(12.4)$ & \\
\hline \multicolumn{4}{|l|}{ Position } \\
\hline House officer & $74(37.6)$ & $18.5(11.1)$ & \multirow{3}{*}{0.741} \\
\hline Medical officer & $93(47.2)$ & $18.1(11.9)$ & \\
\hline Specialist Pediatrician & $30(15.2)$ & $20.0(12.5)$ & \\
\hline \multicolumn{4}{|l|}{ University graduated } \\
\hline Overseas & $80(40.6)$ & $16.9(10.1)$ & \multirow[t]{2}{*}{0.092} \\
\hline Local & $117(59.4)$ & $19.6(12.5)$ & \\
\hline \multicolumn{4}{|c|}{ Number of average calls per month } \\
\hline 4 and below & $68(34.5)$ & $17.5(10.7)$ & \multirow[t]{2}{*}{0.374} \\
\hline 5 and above & $129(65.5)$ & $19.0(12.1)$ & \\
\hline \multicolumn{4}{|c|}{ Duration of pediatrics working experience } \\
\hline Less than 2 years & $122(61.9)$ & $17.3(10.9)$ & \multirow{2}{*}{0.074} \\
\hline 2 years and above & $75(38.1)$ & $20.5(12.6)$ & \\
\hline
\end{tabular}


University (CSc/Sem6(36)2014) and the Medical Research \& Ethics Committee, Ministry of Health Malaysia (NMRR-15-144-24112). Funding including the cash incentives as tokens of appreciation was provided by the International Medical University Research Grant (CSc/ Sem6(36)2014). Participants were given a brief explanation on the objectives of the study. Confidentiality was assured and consent was obtained from the participants.

\section{Statistical analysis}

The Statistical Package for Social Sciences (SPSS) version 16.0 was used to analyse the data in this study. Descriptive analysis was performed on all the variables in the study. The 9 items of EE subscale were summed to obtain the total score for EE. The 10 items of the PSS were summed to obtain the total score for PSS. Normality was assessed for each continuous variable. EE total score was categorized into low, moderate and high to obtain the frequencies. Reliability analysis and exploratory factor structure analysis were conducted to validate the EE subscale. T-test and Analysis of Variance (ANOVA) test were used to compare the mean of emotional exhaustion score across the socio-demographic variables and sources of stress. Pearson correlation was used to assess the correlation between PSS and EE. Multiple linear regression was used to obtain

TABLE 2: Association between emotional exhaustion and perceived sources of job stress among respondents $(n=197)$

\begin{tabular}{|c|c|c|c|}
\hline \multirow[t]{2}{*}{ Sources of job stress } & \multicolumn{2}{|c|}{$\begin{array}{l}\text { Emotional exhaustion } \\
\text { mean (SD) }\end{array}$} & \multirow[t]{2}{*}{$p$ value } \\
\hline & Yes & No & \\
\hline Acute intensive care in children & $19.7(11.0)$ & $16.0(12.7)$ & 0.051 \\
\hline Chronic care in children & $21.1(11.9)$ & $16.2(10.9)$ & 0.003 \\
\hline Crowded wards & $20.7(11.4)$ & $13.4(10.7)$ & $<0.001$ \\
\hline Dealing with difficult parents & $19.3(11.5)$ & $15.5(11.7)$ & 0.072 \\
\hline Dealing with ethical issues e.g. end of life challenges & $20.5(11.8)$ & $15.5(10.8)$ & 0.003 \\
\hline Dealing with patient's psychosocial problem & $21.0(11.4)$ & $15.8(11.3)$ & 0.002 \\
\hline Difficult procedures in children & $21.0(11.0)$ & $16.7(12.2)$ & 0.048 \\
\hline Disrespectful interactions with colleagues/subordinates & $20.6(11.4)$ & $15.6(11.4)$ & 0.003 \\
\hline Emotional relationship & $21.0(11.8)$ & $17.4(11.4)$ & 0.051 \\
\hline Family commitments and obligations & $20.6(11.8)$ & $16.8(11.2)$ & 0.020 \\
\hline Fear of infection & $22.2(12.2)$ & $17.2(11.2)$ & 0.010 \\
\hline Fear of medical errors & $21.5(11.7)$ & $13.8(9.8)$ & $<0.001$ \\
\hline Fear of medico legal issues & $20.6(11.8)$ & $13.6(9.7)$ & $<0.001$ \\
\hline Feeling of inadequate knowledge to meet work demands and objectives & $19.7(11.2)$ & $15.5(12.3)$ & 0.034 \\
\hline Feeling of underpaid & $21.8(11.4)$ & $16.0(11.2)$ & $<0.001$ \\
\hline Feeling uncertain in this career path & $22.3(11.3)$ & $15.3(11.0)$ & $<0.001$ \\
\hline Feeling unsafe during work & $23.6(12.4)$ & $17.4(11.2)$ & 0.008 \\
\hline Financial difficulties & $21.9(13.0)$ & $17.6(11.1)$ & 0.059 \\
\hline Grief and guilt about patient death or unsatisfactory outcome & $18.7(12.0)$ & $18.4(11.4)$ & 0.862 \\
\hline Hostile workplace environment & $22.8(10.6)$ & $17.1(11.6)$ & 0.002 \\
\hline Insufficient protected research time or funding & $19.6(12.2)$ & $17.9(11.3)$ & 0.351 \\
\hline Insufficient protected time for continuous medical education or learning & $20.8(10.8)$ & $16.3(12.1)$ & 0.007 \\
\hline Involvement of mentor- mentee program & $20.8(11.6)$ & $18.0(11.6)$ & 0.017 \\
\hline Lack of appreciation from patients or their parents & $22.4(14.0)$ & $17.3(10.5)$ & 0.021 \\
\hline Lack of appreciation from supervisors & $22.3(11.3)$ & $15.9(11.2)$ & $<0.001$ \\
\hline Lack of facilities as workstation or for doctors on call & $20.6(12.0)$ & $17.0(11.2)$ & 0.031 \\
\hline Lack of incentives and promotions & $21.9(12.0)$ & $15.8(10.6)$ & $<0.001$ \\
\hline Lack of opportunity in career training & $20.0(11.3)$ & $17.1(11.8)$ & 0.074 \\
\hline Lack of resources when dealing with faulty equipments & $20.1(11.6)$ & $15.3(11.0)$ & 0.006 \\
\hline Language barrier with patients & $20.7(12.0)$ & $17.4(11.3)$ & 0.072 \\
\hline Nurse - physician conflicts & $21.4(11.4)$ & $16.4(11.4)$ & 0.003 \\
\hline Physical or mental health problems & $23.9(12.7)$ & $17.1(10.8)$ & 0.003 \\
\hline Setting unrealistic goals of having them imposed on oneself & $21.7(12.1)$ & $17.5(11.3)$ & 0.004 \\
\hline Time pressures and deadlines to meet & $22.9(11.3)$ & $14.2(10.3)$ & $<0.001$ \\
\hline Unnecessary administrative paperwork and red tapes & $20.3(12.0)$ & $15.8(10.5)$ & 0.006 \\
\hline $\begin{array}{l}\text { Work demands affect personal and home life/imbalance between } \\
\text { career and family }\end{array}$ & $21.3(11.6)$ & $14.2(10.4)$ & $<0.001$ \\
\hline Work overload, on calls and long working hours & $20.5(11.2)$ & $15.0(11.6)$ & 0.002 \\
\hline Working with incompetent subordinates/colleagues & $19.6(11.6)$ & $17.6(11.6)$ & 0.229 \\
\hline
\end{tabular}


the most important predictors of emotional exhaustion. Collinearity and other assumptions were checked for and a $p$ value $<0.05$ was set as the level of significance.

\section{RESULTS}

\section{Socio-demographic characteristics}

One hundred and ninety-seven participants returned complete questionnaires (response rate of $65 \%$ ). The responders were more likely to be females (72.6\%), married (52.3\%), Malay (47.2\%), aged less than 30 years $(61.4 \%)$ and graduated overseas $(59.4 \%)$. The majority were medical officers $(47.2 \%)$ and had working experience of less than two years $(61.9 \%)$ (Table 1$)$.

\section{Sources of job stress among respondents}

The most common sources of stress reported by respondents were: "dealing with difficult parents" $(80.2 \%)$, "feeling of inadequate knowledge to meet work demands" $(72.6 \%)$, "crowded wards" (70.6\%), "fear of medico legal issues" $(70.1 \%)$ and "dealing with acute intensive care children" $(68.5 \%)$.

\section{Factorial based validity and internal consistency of the EE}

Factorial validity of the EE was examined using exploratory factor analysis. It showed that the English version of EE used in this study has one factor which supports that EE is one component. Cronbach's alpha for the 9 items of the EE was 0.93. This indicates that the EE subscale is a valid and a reliable instrument for measuring "emotional burnout" among Malaysian doctors.

Emotional exhaustion and its associated factors

Using the EE subscale of the MBI-HSS, the EE total score was categorized into low, moderate and high by summing the raw scores and then categorizing as low (less or equal to 16), moderate (17-26) or high (greater or equal to 27). ${ }^{21,24}$ The mean EE of doctors was $18.5 \pm 11.6$ and the EE score ranged from 0 to 48 .

Fifty doctors $(25.4 \%)$ showed high, $48(24.4 \%)$ showed moderate and $99(50.2 \%)$ showed low emotional exhaustion. To examine the factors associated with emotional exhaustion in bivariate analysis, we used the total score of emotional exhaustion as a continuous variable. There was no significant association between emotional exhaustion and the socio-demographic variables $(\mathrm{p}>0.05)$ (Table 1). To examine the association between emotional exhaustion and perceived sources of job stress, mean total score emotional exhaustion was compared between those who answered "yes" and those who answered "no" on each source of stress. Table 2 showed that 29 out of the 38 items showed significant association with emotional exhaustion $(\mathrm{p}<0.05)$ in which the mean EE score was higher among those who answered "yes" compared to those who answered "no". Pearson correlation analysis showed positive and significant correlation between PSS and emotional exhaustion $(\mathrm{r}=0.625, \mathrm{p}<0.001)$.

In the multivariate analysis (Table 3 ), all the variables showing significant association with emotional exhaustion were included. The adjusted $\mathrm{R}$ square $=0.48$ meant that $48 \%$ of the variability of Emotional Exhaustion is explained by the model. The total model was significant $(p<0.05)$. Collinearity statistics shows no collinearity between the variables because the values of tolerance and variance inflation factor are within the recommended values.

\section{DISCUSSION}

The MBI-HSS inventory consisted of three subscales: EE, Depersonalization and Personal

TABLE 3: Multivariate analysis: predictors of emotional exhaustion

\begin{tabular}{|c|c|c|c|c|c|}
\hline & \multirow[t]{2}{*}{ B } & \multirow[t]{2}{*}{ Beta } & \multirow[t]{2}{*}{$p$} & \multicolumn{2}{|c|}{$95 \% \mathrm{CI}$} \\
\hline & & & & Lower & Upper \\
\hline Perceived stress score & 1.373 & 0.574 & $<.001$ & 1.111 & 1.635 \\
\hline Dealing with difficult parents & 2.999 & -0.103 & 0.073 & 0.281 & 6.279 \\
\hline Dealing with patient's psychosocial problem & 2.907 & 0.125 & 0.023 & 0.399 & 5.415 \\
\hline Disrespectful interactions with colleagues/subordinates & 2.719 & 0.115 & 0.041 & 0.118 & 5.321 \\
\hline Lack of appreciation from supervisors & 3.379 & 0.143 & 0.019 & 0.563 & 6.194 \\
\hline Lack of incentives and promotions & 3.010 & 0.129 & 0.032 & 0.267 & 5.753 \\
\hline Lack of opportunity in career training & 2.727 & -0.118 & 0.055 & -5.513 & 0.059 \\
\hline Time pressures and deadlines to meet & 4.403 & 0.190 & 0.001 & 1.782 & 7.024 \\
\hline Setting unrealistic goals of having them imposed on oneself & 3.242 & -0.120 & 0.035 & 0.232 & 6.253 \\
\hline
\end{tabular}

B: Regression estimate; Beta: Standardized co-efficient; CI: Confidence Interval. 
Accomplishment. ${ }^{1}$ We used the EE subscale to measure "emotional exhaustion" because it is the most significant dimension of burnout in the MBI. The EE dimension refers to the feeling of being drained and fatigued emotionally and psychologically from work. ${ }^{25}$ It was reported that $\mathrm{EE}$ is a critical element of burnout in the literature and it is the most widely reported and analyzed dimension among the three subscales of burnout. Maslach et al., reported that "when people describe themselves as experiencing burnout, they are most often referring to the experience of emotional exhaustion". ${ }^{26}$ In addition, EE has been shown to lead to depersonalization and cynicism. ${ }^{27}$

This study is the first in Malaysia exploring the factors associated with emotional exhaustion in the pediatric setting. Pediatricians have a higher risk of professional burnout, given the frequency, duration, and emotional intensity of bi-directional clinical interactions between children and their caregivers. $^{28}$

Of the 197 doctors surveyed, 25.4\% showed high level of emotional exhaustion. A similar rate was reported among pediatricians in Argentina. ${ }^{29}$ Prevalence rates were higher in Saudi Arabia $(34 \%)^{4}$ but lower in Germany $(10 \%) .^{28}$

This study found that perceived stress, clinical management and clinical work environmental factors exhibited significant associations with emotional exhaustion. Reported figures on affected pediatricians vary across nations. Most studies hypothesize that pediatrician's emotional burnout is associated with demographic characteristics, hospital work environment and resources, clinical management or personal factors..$^{28}$ The demographic data here reported did not exhibit significant associations with emotional exhaustion. Similar findings were reported recently. ${ }^{30}$ Pediatrics, a multi-disciplinary practice that includes emergency and intensive care, general pediatrics, neonatology, and subspecialties, generates a workload that is physically and mentally demanding. ${ }^{31}$ There was a significant association between patient's psycho-social problem and emotional exhaustion. The need for tedious repetition to explain patient's treatment needs, potential side-effects, interruption of school and social routines, suspension to leisure and to mitigate caregivers' anxiety with the need to assimilate treatment information could explain this association. ${ }^{32}$ Substantial work stress triggers increased exhaustion and reduced vigor in daily clinical work. ${ }^{31}$ This study showed significant correlation between work stress and emotional exhaustion among pediatricians. Weigl et al. reported similar findings. ${ }^{28}$

Some limitations in this communication have to be mentioned. Firstly, its cross sectional design hinders the possibility of establishing a cause and effect relationship in contrast with achieved by Pantaleoni et al. ${ }^{5}$ Furthermore, doctors here involved vary from house-officers to pediatricians and therefore differ in experiences and in duration of exposure into the pediatric discipline. The high percentage of young inexperienced pediatric doctors could be reflected from the glut of medical graduates over the recent years. ${ }^{33}$ To address this limitation, we used univariate and multivariate analysis to adjust for confounders. Another consideration is that doctors were assigned to different rotations (e.g. intensive care rotations versus outpatient care) when the study was conducted, so experienced different level of clinical workload. This could influence their attitude towards work and their questionnaire responses.

Despite these limitations, this study offers a deeper insight into the continuous education and training of a pediatric doctor. Registered results exhibited significant associations between a myriad of perceived work related stressors with pediatricians' emotional exhaustion. Performance pressures that impose time limitations were significantly associated with pediatricians' emotional exhaustion. Similarly, workplace factors such as unrealistic goals and disrespectful interactions with colleagues or subordinates were significantly associated with emotional exhaustion. These results reveal similar to those obtained in previous studies..$^{21,24,34}$ Although prospective evidence on the impact of organizational contextual stressors of emotional exhaustion in pediatricians is scarce, studies in other medical specialties corroborate the impact of effort-reward imbalance on burnout. ${ }^{28}$ Regardless of recent salary adjustments, ${ }^{24}$ imbalanced remuneration, lack of incentives, promotion and appreciation from supervisors remained significant factors associated with emotional exhaustion in this, as in previous similar studies. ${ }^{24,28,35}$ The Effort-Reward Imbalance Model requires the balance between work efforts and rewards to be executed through three domains: salary, prestige, and job security. ${ }^{24,28}$

In conclusion, these data indicate that emotional exhaustion of doctors in Pediatric 
departments at public hospital was high and related with sources of stress in the workplace and the level of self-perceived stress but not with socio-demographic factors. Consequently, these sources should be addressed and appropriately managed to improve the pediatrics working environment and thereby enhance efficiency and job satisfaction.

\section{Abbreviations:}

ANOVA: Analysis of Variance; EE: Emotional Exhaustion; MBI-HSS: Maslach Burnout Inventory-Human Service Survey; PSS: Perceived Stress Scale; SPSS: Statistical Package for Social Sciences.

\section{REFERENCES:}

1. Maslach C, Jackson SE. The measurement of experienced burnout. J Occup Health 1981;2:99-113.

2. Pistelli Y, Perochena J, Moscoloni N, Tarrés MC. Síndrome de desgaste profesional en médicos pediatras. Análisis bivariado y multivariado. Arch Argent Pediatr 2011;109(2):129-34.

3. Martins AE, Davenport MC, Del Valle MP, et al. Impact of a brief intervention on the burnout levels of pediatric residents. J Pediatr (Rio J) 2011;87(6):493-8.

4. Al-Youbi RA, Jan MM. Burnout syndrome in pediatric practice. Oman Med J 2013;28(4):252-4.

5. Pantaleoni JL, Augustine EM, Sourkes BM, Bachrach LK. Burnout in pediatric residents over a 2-year period: a longitudinal study. Acad Pediatr 2014;14(2):167-72.

6. Wright JG, Khetani N, Stephens D. Burnout among faculty physicians in an academic health science centre. Paediatr Child Health 2011;16(7):409-13.

7. Cavaliere TA, Daly B, Dowling D, Montgomery K. Moral distress in neonatal intensive care unit RNs. Adv Neonatal Care 2010;10(3):145-56.

8. ConradD, Kellar-Guenther Y.Compassionfatigue, burnout, and compassion satisfaction among Colorado child protection workers. Child Abuse Negl 2006;30(10):1071-80.

9. Roth M, Morrone K, Moody K, Kim M, et al. Career burnout among pediatric oncologists. Pediatr Blood Cancer 2011;57(7):1168-73.

10. Jan MM. Perception of pediatric neurology among nonneurologists. J Child Neurol 2004;19(1):1-5.

11. Branco RG, Garcia TT, Molon ME, Garcia PCR, et al. 1138 Burnout Syndrome Among Pediatricians: A Case Control Study Comparing Pediatric Intensivists and General Pediatricians. Pediatr Res 2010;68:564.

12. Passalacqua SA, Segrin C. The effect of resident physician stress, burnout, and empathy on patient-centered communication during the long-call shift. Health Commun 2012;27(5):449-56.

13. Shanafelt TD, Balch CM, Bechamps G, Russell T, et al. Burnout and medical errors among American surgeons. Ann Surg 2010;251(6):995-1000.

14. Piko BF. Burnout, role conflict, job satisfaction and psychosocial health among Hungarian health care staff: A questionnaire survey. Int J Nurs Stud 2006;43(3):311-8.

15. BrownSD, GoskeMJ,Johnson CM. Beyond substance abuse: stress, burnout, and depression as causes of physician impairment and disruptive behavior. J Am Coll Radiol 2009;6(7):479-85.
16. Dyrbye LN, Thomas MR, Massie FS, Power DV, et al. Burnout and suicidal ideation among U.S. medical students. Ann Intern Med 2008;149(5):334-41.

17. Sonneck G, Wagner R. Suicide and burnout of physicians. OMEGA-J Death Dying 1996;33:255-63.

18. Rogers AC. Vulnerability, health and health care. J Adv Nurs 1997;26(1):65-72.

19. The World Bank: World Development Indicators 2015. [Accessed on: January 30, 2016] Available at: http:/ / data. worldbank.org/indicator

20. National Specialist Register: Malaysia. General Paediatrics 2015. [Accessed on:January 20, 2016] Available at: https: / / www.nsr.org.my / list1view.asp?page $=1$

21. Al-Dubai SAR, Rampal KG. Prevalence and associated factors of burnout among doctors in Yemen. Field Study. J Occup Health 2010;52(1):58-65.

22. Al-Dubai SAR, Al-Shaggaa MA, Rampal KG, Sulaiman NA. Factor structure and reliability of the Malay version of Perceived Stress Scale among medical students. Malays J Med Sci 2012;19(3):43-9.

23. Al-Dubai SAR, Ganasegeran K, Barua, Rizal AAM, et al, Evaluation of psychometric properties of the Malay version Perceived Stress Scale in two occupational settings in Malaysia. Ann Med Health Sci Res 2014;4(Suppl 2):S104-7.

24. Al-Dubai SAR, Ganasegeran K, Perianayagam W, Rampal KG. Emotional Burnout, Perceived Sources of Job Stress, Professional Fulfillment, and Engagement among Medical Residents in Malaysia. ScientificWorldJournal 2013;2013:137620.

25. Lambert EG, Barton-Bellessa SM, Hogan NL. The Consequences of Emotional Burnout Among Correctional Staff. Sage Open 2015;5(2):1-15.

26. Maslach C, Schaufeli W, Leiter M. Job burnout. Annu Rev Psychol 2001;52:397-422.

27. Maslach C, Leiter M. Early predictors of job burnout and engagement. J Appl Psychol 2008;93(3):498-512.

28. Weigl M, Schneider A, Hoffmann F, Angerer P. Work stress, burnout, and perceived quality of care: a crosssectional study among hospital paediatricians. Eur J Pediatr 2015;174(9):1237-46.

29. Galván ME, Vassallo JC, Rodríguez SP, Otero P, et al. Síndrome de desgaste profesional (burnout) en médicos de unidades de cuidados intensivos pediátricos en la Argentina. Arch Argent Pediatr 2012;110(6):466-73.

30. Aksoy DY, Durusu Tanriover M, Unal S, Dizdar O, et al. Burnout syndrome during residency in internal medicine and pediatrics in a country without working time directive. Int J Health Care Qual Assur 2014;27(3):223-30.

31. Pantaleoni JL, Augustine EM, Sourkes BM, Bachrach LK. Burnout in Pediatric Residents Over a 2-Year Period: A Longitudinal Study. Acad Pediatr 2014;14(2):167-72.

32. Kohlsdorf M, Costa Jr AL. Psychosocial Impact of Pediatric Cancer on Parents: A Literature Review. Paidéia (Riberãon Preto) 2012;22(51):119-29.

33. Quek DKL. "The Standards of Medical Education in Malaysia and Its Acceptability. Medico-Legal Society of Malaysia Conference. Royale Chulan Hotel, Kuala Lumpur. 16 Nov. 2011. [Accessed on: October 25, 2016] Available at: http: / / www.mpsr.org/2011/12/the-standards-ofmedical-education-in-malaysia-and-its-acceptability /

34. Yusoff MSB, Jie TY, Esa AR. Stress, stressors and coping strategies among house officers in a Malaysian hospital. ASEAN Journal of Psychiatry 2011;12(1):1-10.

35. Bowden MJ, Mukherjee S, Williams LK, DeGraves S, et al. Work-related stress and reward: an Australian study of multidisciplinary pediatric oncology healthcare providers. Psychooncology 2015; 24(11):432-8. 